\title{
Applications (Ideas) in Linear Algebra with Digital Image Processing. Can we Do, Teach, Motivate and Evaluate?
}

\author{
C. M. R. Caridade ${ }^{1 *}$ \\ ${ }^{1}$ Department of Mathematics and Physics, Polytechnic of Coimbra-Institute of Engineering, Coimbra, PORTUGAL
}

*Corresponding Author: caridade@isec.pt

Citation: Caridade, C. M. R. (2019). Applications (Ideas) in Linear Algebra with Digital Image Processing. Can we Do, Teach, Motivate and Evaluate?. Journal of Information Systems Engineering \& Management, 4(4), em0103. https://doi.org/10.29333/jisem/6347

Published: December 7, 2019

\begin{abstract}
The application of new methodologies in higher education brings with it questions such as: "Can we do it?", "Can we teach?", "Can we motivate students?", "Can we evaluate?". During the last 8 years, in the Linear Algebra course of the Mechanical and Electromechanical Engineering of the Polytechnic of CoimbraInstitute of Engineering, it has been trying to answer these questions. The teaching methodology presented consists in the approach of Linear Algebra contents, using digital Image Processing applications. This new environment is intended to encourage students to learn the concepts and their manipulation in a productive and dynamic way. From the analysis of the studies and the student's opinions (students' adherence and motivation, questionnaires), it has been found that the use of this new teaching methodology helps the 'learning to learn' as long as it is well defined, with clear objectives for those who implements (teacher) and who interacts (students) with it.
\end{abstract}

Keywords: teaching mathematics, linear algebra, image processing

\section{INTRODUCTION}

As in many other universities, Polytechnic of Coimbra-Institute of Engineering (PC-IE) offers basic curricular units of mathematics in the first year of all engineering. This curricular units are responsible for theoretical basis necessary for professional's future in Engineering, and for this they are present in most of the degrees taught in various higher education institutions. For students the basic math contents are difficult especially if they are abstract and theoretical. Fortunately, much of the mathematical content can be presented using practical applications to justify their study and arouse interest from students. The manipulation of mathematical concepts and their connection can be explored using methodological strategies in mathematical disciplines. An appropriate teaching strategy that allows the student to develop his or her critical spirit, understand the main concepts and apply them to a variety of situations is very important for effective learning (Caridade, 2019).

In view of the above findings, during the last 8 years, in Linear Algebra course (LA), mathematical content has been explored through practical applications of digital image processing. The Digital Image Processing (DIP) is a set of techniques and methods applied to digital images very useful nowadays. The algorithms developed in digital images are extremely rich in mathematical concepts and are one interesting pedagogical tool to explore LA concepts (Gonzalez et al., 2009). Some experiences have been made, for example the work presented by Professor Silverman and Rosen (2010) that uses the DIP and LA to teach concepts and terminologies of LA while developing self-confidence students. The DIP helps to develop visual and intuitive understanding of the concepts, which are usually abstract and entirely new for students (Berriochoa et al., 2009; Caridade et al., 2014; Donevska-Todorova, 
Table 1. Correspondence between LA and DIP

\begin{tabular}{ll}
\hline Linear Algebra & Image Processing \\
\hline Basic concepts of matrices & Image representation \\
\hline Matrix operations and proprieties & Image operations and proprieties \\
\hline Linear combination & Image operations \\
\hline Geometric transform & Polygons matrix operations \\
\hline Block matrix manipulation and operations & Block image operations \\
\hline Random matrices & Create random images; create videos \\
\hline Eigenvectors and eigenvalues & Image compression, Image segmentation \\
\hline
\end{tabular}

2018; Garía and Cano, 2018). So, the DIP can improve the teaching of LA in a completely different way by increasing the motivation and participation.

LA concepts like linear equations, algebra matrix, matrix operations, matrix transformations, and inverse transformation can be explored using applications of DIP (image representation, image transformation, image enhancement, image restoration, image segmentation or image compression) (Zin et al., 2015). Image filtering techniques are usually applied to increase the quality of magnetic resonance images, segmentation of skin cancer in dermoscopy images, edge detection techniques for fingerprint images, etc. All this Image Processing techniques involve LA subjects. The concepts to be learned by the students must be meaningful for them, so that they can assimilate it. Using matrices operations to eliminate the image background or identify parts of the image can enrich teaching practices and improve student learning. The use of the $2 \mathrm{D}$-geometric transformation can bring one image into alignment with another increasing the motivation and improvement of student's skills in these concepts. LA and DIP can be taught simultaneously. With these combined lessons, it is hoped that students can overcome the difficulties in learning LA through the real-world applications. Furthermore, teachers are also able to teach the contents of LA to students in a more stimulating and motivating environment.

The work presented in this paper is a collection of applications developed for engineering students where LA contents are learned through DIP. Students' opinions on these initiatives are also presented in order to evaluate their pedagogical and motivational interest as well as identify possible changes to make to Curricular Unit (UC). The paper is organized in 6 parts. A first part with the introduction, in the second part is presented the Linear Algebra Curricular Unit (LA-UC) and in the third the methodology applied to LA-UC. In the fourth part monitoring and evaluation, in the fifth part the results and finally in the last part are presented the conclusions and future work.

\section{LINEAR ALGEBRA CURRICULAR UNIT}

The LA-CU is available to all students of the first year in Mechanical and Electromechanical Engineering degree in Polytechnic of Coimbra-Institute of Engineering. During the theoretical and practical lessons, a new teaching methodology are presented to the students, using a stimulating and interesting learning environment where DIP interacts with LA. To enrich this interconnection a practical project developed in Matlab is presented to the students. The contents of LA are presented to students as practical applications developed with DIP techniques. In Table 1 it is possible to observe the correspondence of some of the LA contents with DIP.

\section{CURRICULAR UNIT METHODOLOGY}

A digital image is a two-dimensional discrete function $f(x, y)$ with $(x, y) \in Z^{2}$ where each pair of coordinates is called a pixel. Without loss of generality, one image can be represented by a matrix, named for example $A$ where each element $a_{i j}$ corresponds to the value of the pixel image position $(i, j)$ (Gonzalez et al., 2009). The binary image is a matrix where $f(x, y)$ is zero (black color) or one (white color). The grayscale image is also a matrix with integer values that measures the pixel intensity, so $f(x, y)$ usually set from 0 (black color) to 255 (white color). The color image (in this case RGB space) are a compose of three matrices that represent Red, Green and Blue space color respectively. The $f(x, y)$ value is a vetor with three parameters that correspond to the three spaces with integer values from 0 to 255 (Gonzalez et al., 2009). In Figure 1 images are represented by binary, grayscale and color form. The students can calculate the size of the images, the values of each pixel in the different forms of the image's representation and can convert the color image to grayscale and then to binary images. All the examples presented in this paper were made in the practical project by the students. 

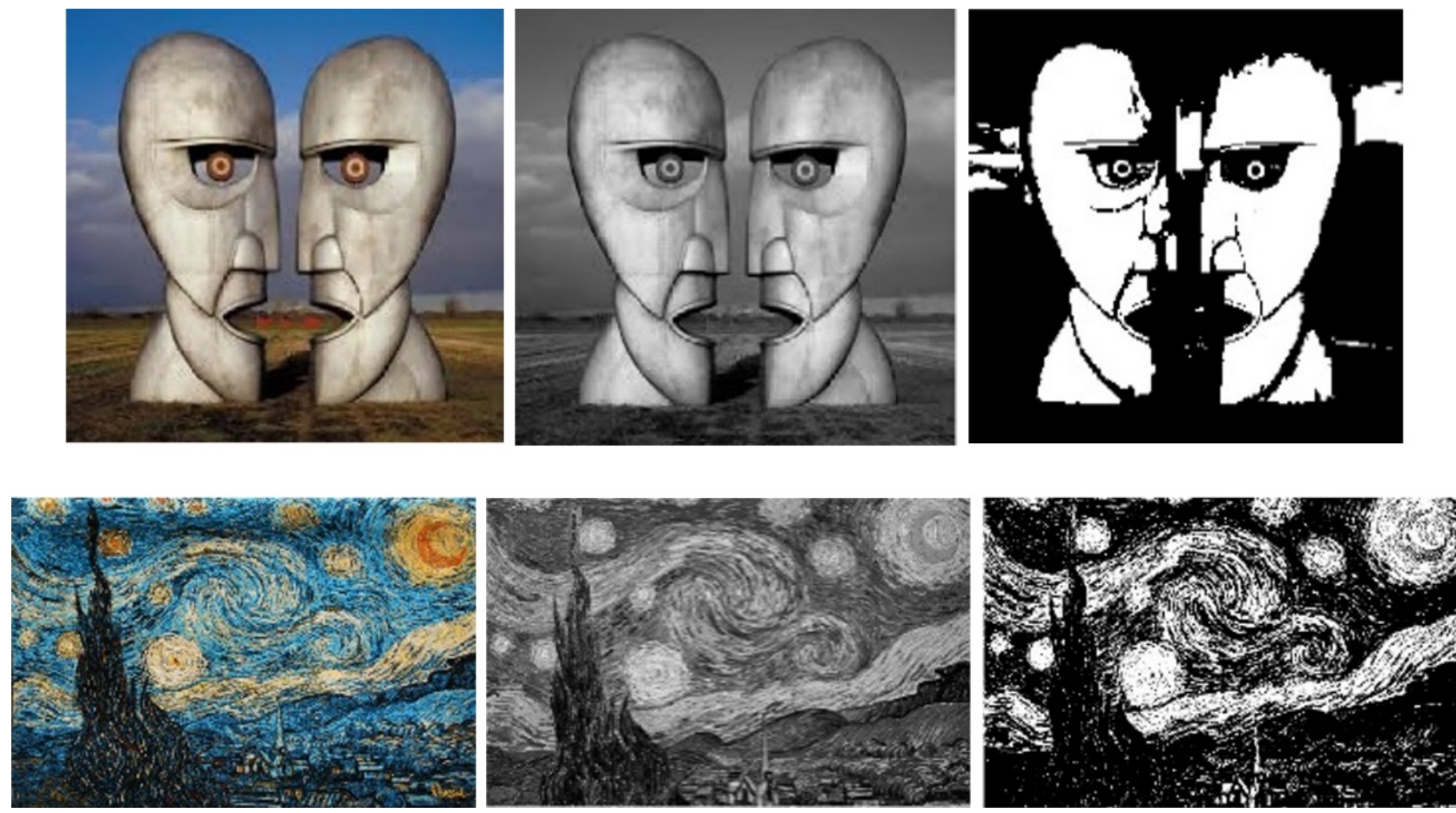

Figure 1. Two digital images repesentations: rgb image (left); grayscale image (center); binary image (right) (Thetapestryhouse.com, n.d.; wikipedia.org, n.d.a)

A

B
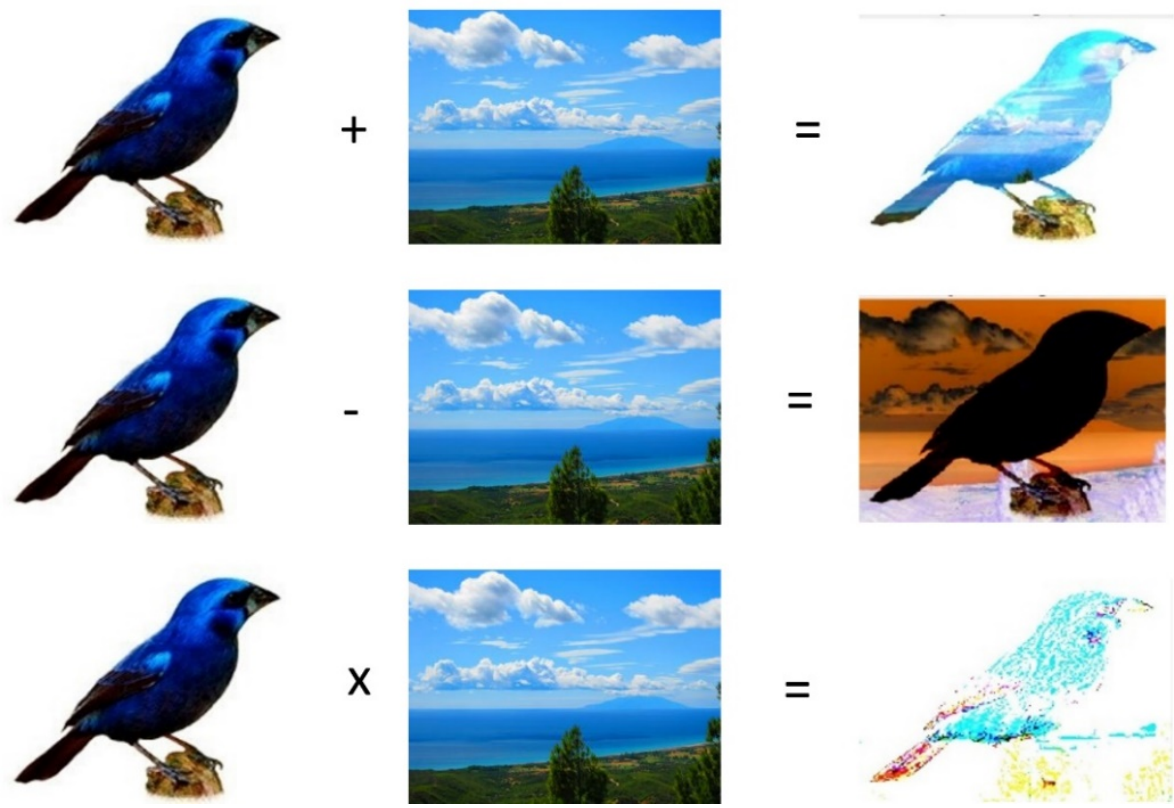

Figure 2. Some matrix operations using digital images (Produto.mercadolivre.com.br, n.d.)

All standard forms to manipulate images can be obtained by applying mathematical operations to the matrix associated with images (Bovik, 2000). Students build new images (matrices) by using elementary operations between matrices. Test their properties and constraints. Thus, it is possible with the images, for example, to verify the associative property between 3 matrices and the fact that the sum is only possible between matrices of the same dimensions. In Figure 2 and 3 some operations between images are presented.

Linear combinations and linear systems are central concepts in LA. Therefore, the experience in the realization of linear combinations between matrices is of extreme importance for the learning of this concept. In this way students are asked to develop linear combinations between two different matrices but with the same dimensions. In Figure 4, a linear combination of two images were proposed. The image, A (the first one) and B (the last one), are combined using the equation $(1-k) A+k B$, white $k=1 / 20$. This is a beautiful example where the matrices operations can be applied, and the result is amazing. 


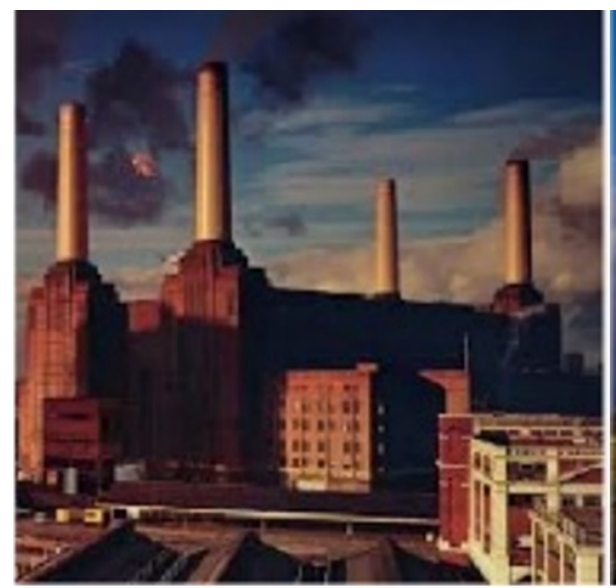

A

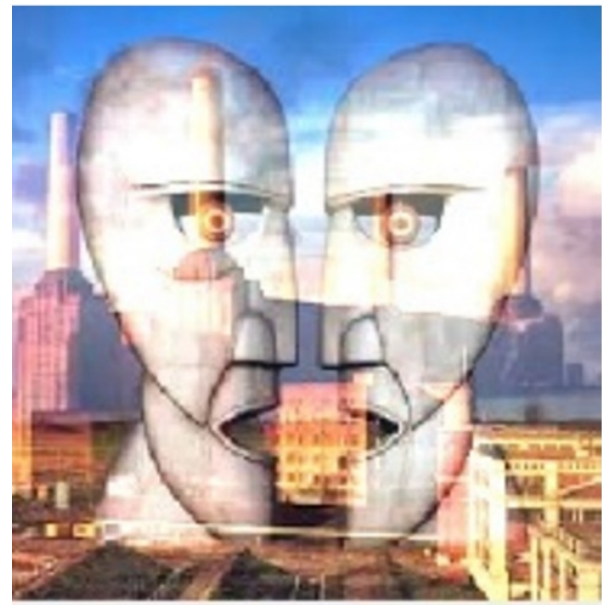

A+B

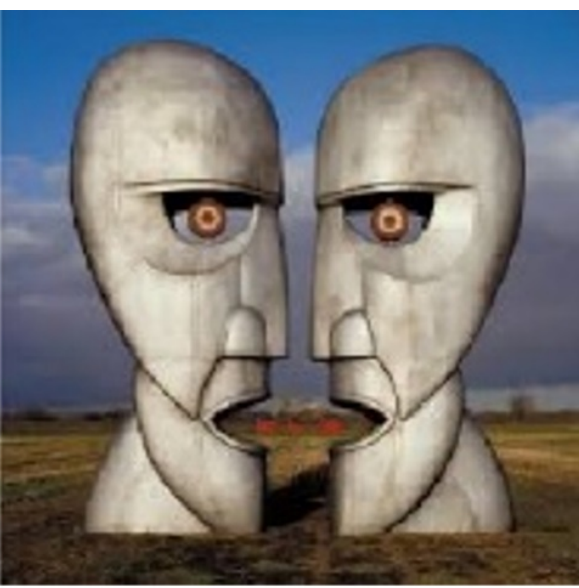

B

Figure 3. Some matrix operations using digital images (wikipedia.org, n.d.a, n.d.b)

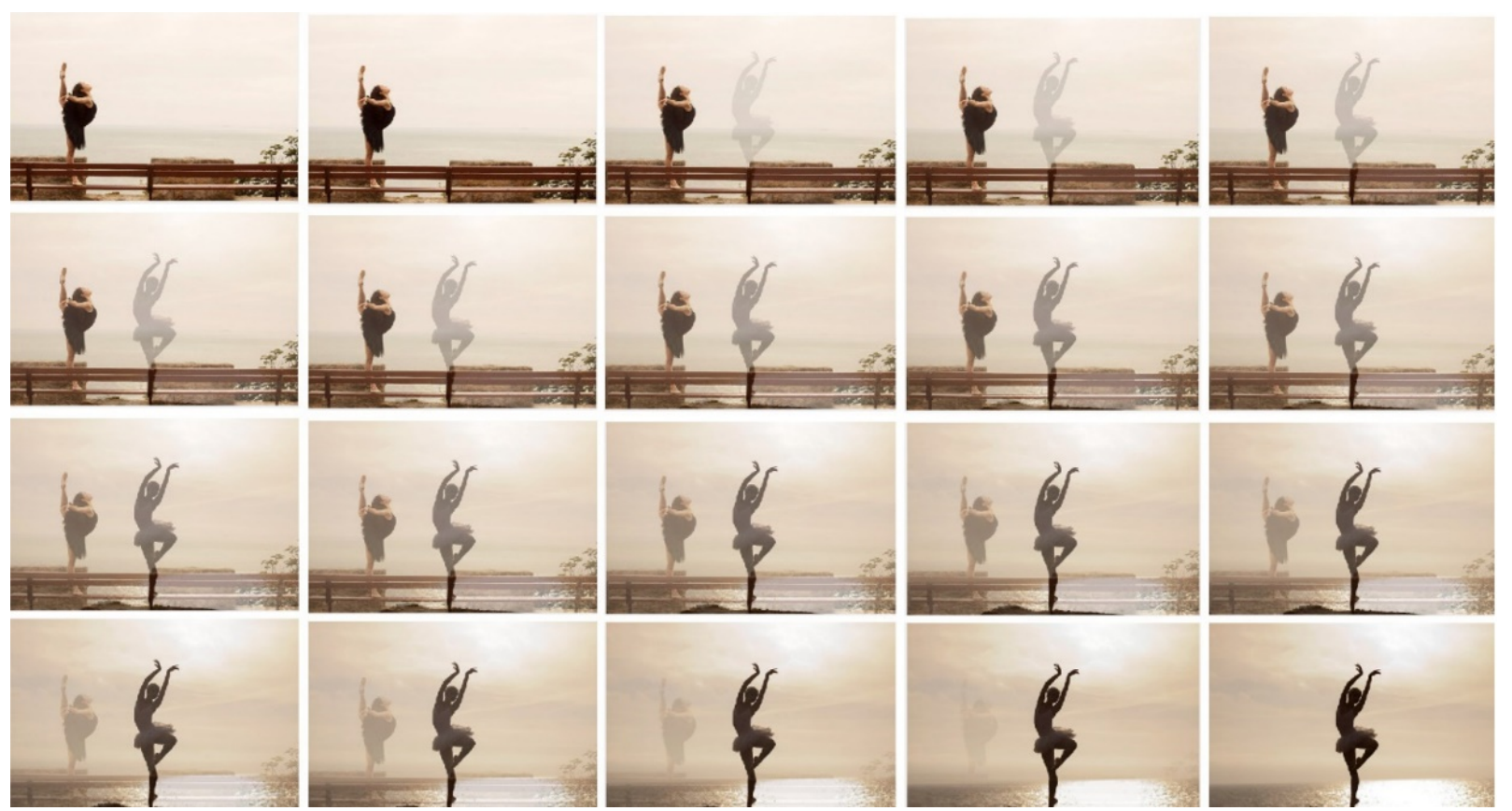

Figure 4. Example of Linear combinatios of two different imagens (Pinterest, n.d.)

Matrix operations can be performed in an interactive user environment and in an intuitive way. Thus, students were asked to create a Graphical User Interface (GUI) in Matlab that was developed to run on any computer or on a web page, such as the LA-CU page. In Figure 5 are presented two of these user-friendly interfaces that make it easier to operate and learn matrix operations. The user can choose the images (matrices) to operate and can, with just one click, perform the matrix operations as desired. 


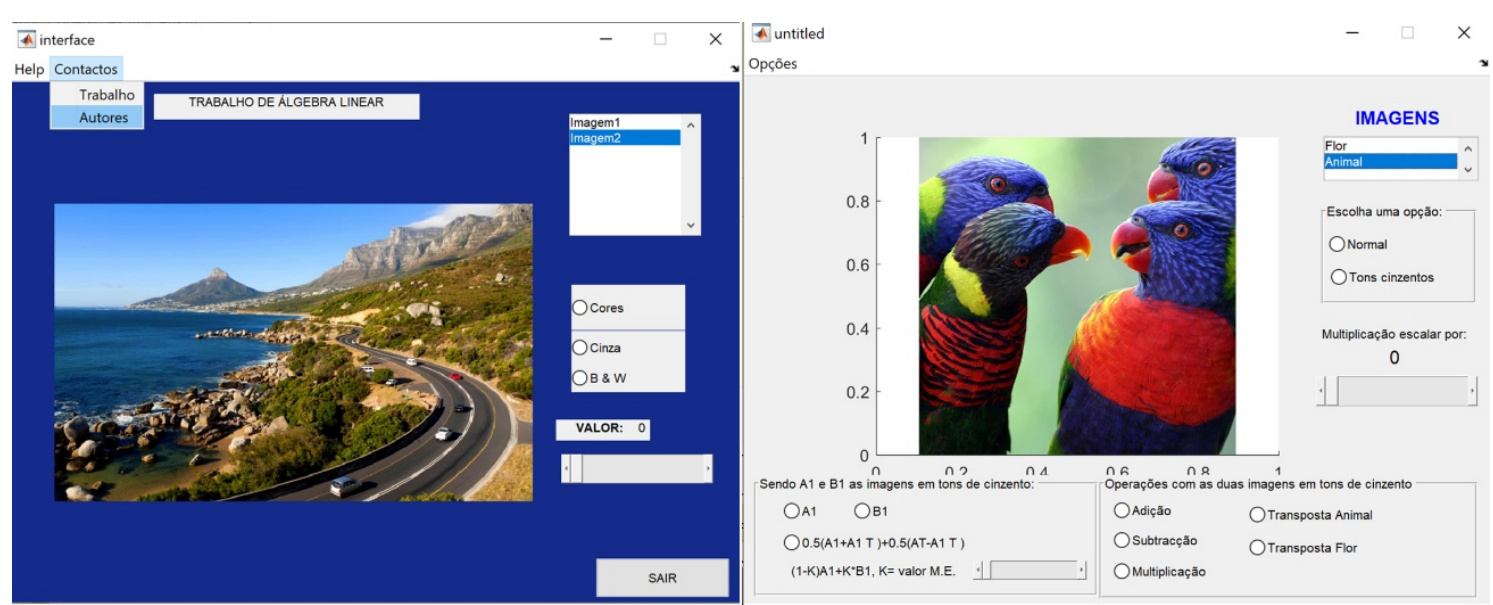

Figure 5. Graphical interfaces developed in Matlab

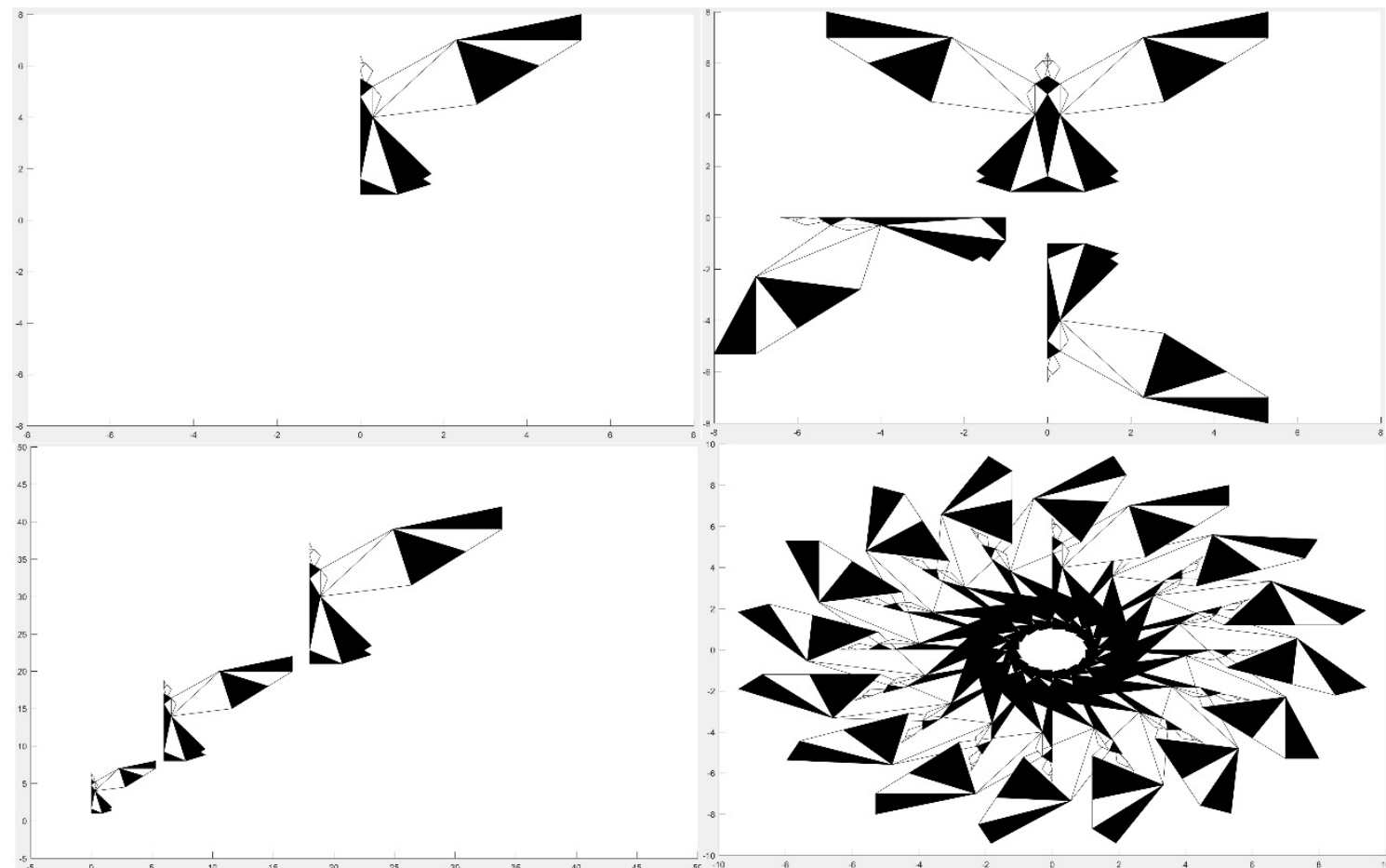

Figure 6. Geometric transformation: polygons image (a - top left), refletions (b - top right), scale change (c bottom left) and rotation ( $\mathrm{d}$ - bottom right)

A 2D vector could be represented by an ordered pair (x,y) but it could also be represented by a line matrix $\left[\begin{array}{ll}x & y\end{array}\right]$. Polygons could also be represented in matrix form, by simply place all the coordinates of the vertices into one matrix. The Geometric transformations such as reflection, scale change and rotation, can be performed by multiplying the vertices of the polygons by the transformation matrix. For example a square with the following vertices $(1,1),(-1,1),(-1,-1)$ and $(1,-1)$ can be described by the matrix $\left[\begin{array}{cc}1 & 1 \\ -1 & 1 \\ -1 & -1 \\ 1 & -1\end{array}\right]$ and to make the reflection in the $\mathrm{x}$-axis is necessary to multiply this matrix by the reflection matrix $\left[\begin{array}{cc}1 & 0 \\ 0 & -1\end{array}\right]$. The example shown in Figure 6 is a set of polygons that define polygonal areas which are filled or unfilled to simulate the left part of a butterfly (Figure 6a)). These sets of polygons can be reflective around the $\mathrm{x}$-axis, the $\mathrm{y}$-axis, and the $\mathrm{y}=-\mathrm{x}$ line by obtaining the images on the bottom right, top left, and bottom left of Figure $6 \mathrm{~b}$ respectively. Other geometric transformations can be applied to the image in Figure 6a) such as scaling (Figure 6c) and rotation (Figure 6d).

Sam Loyd perhaps America's greatest ever puzzle maker, invented and refined thousands of puzzles in his lifetime (Mathsisfun.com, n.d.). One of the puzzles invented by Sam was the Sliding Block Puzzle and the original version was made with 15 wooden blocks in a tray. A block or submatrix of a matrix A is any matrix obtained from A by deleting rows and columns. The image (matrix) chosen by the students is divided into matrix blocks (sub- 

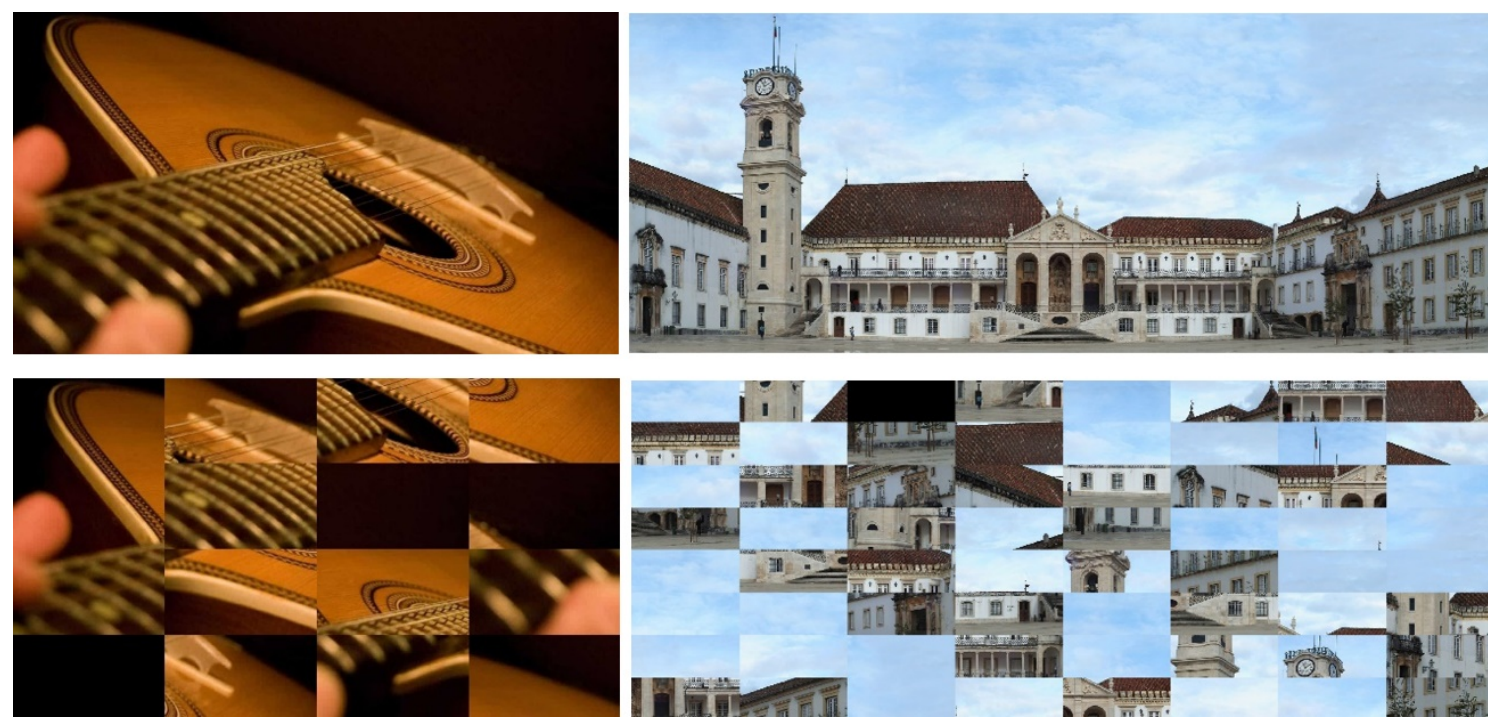

Figure 7. Sliding Block Puzzle image using 16 (left) and 64 (right) blocks (Notícias ao Minuto, n.d.; wikipedia.org, n.d.c)
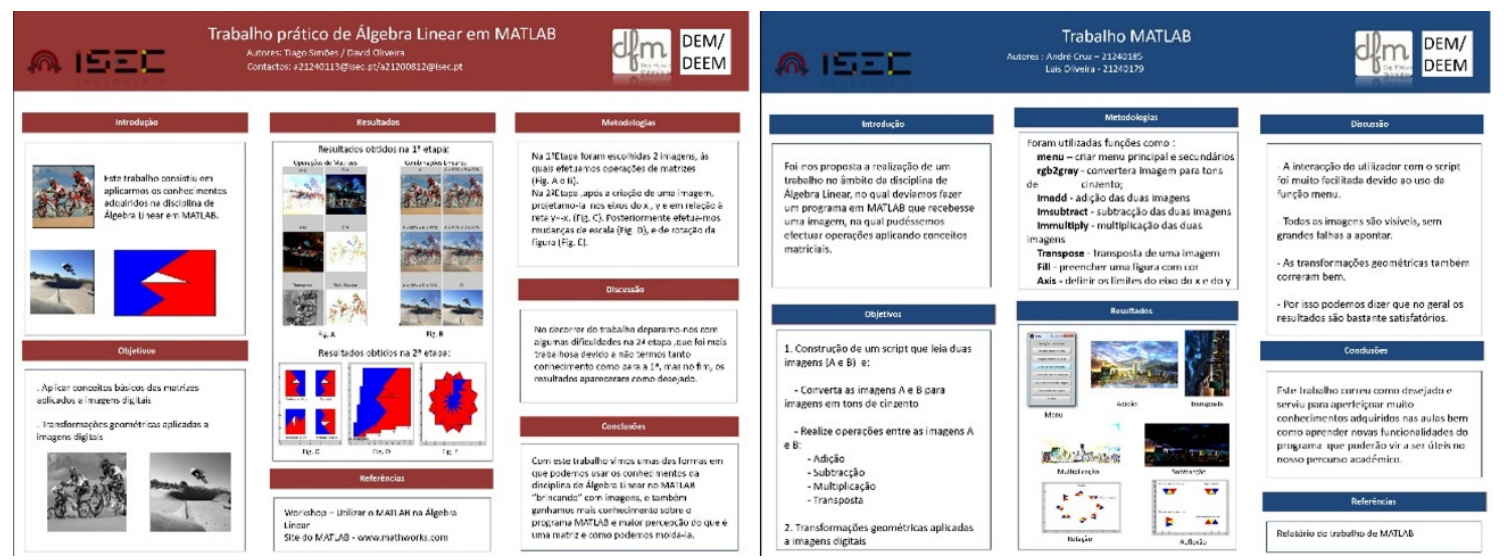

Figure 8. Posters developed by the students

matrices) that are randomly mixed to simulate a Sliding Block Puzzle. Then one of the blocks, also randomly, is filled with black to simulate the empty block of the puzzle. Figure 7 shows two simulations of the puzzle. The first puzzle (left) consists of 16 (4x4 sub-matrices) blocks is an image of a traditional Coimbra's guitar and the second by 64 blocks (8x8 sub-matrices) is the image of the Coimbra's University.

These are some applications with DIP using LA developed in practical projects by the engineering students. Other ones can be seen in previous publications (Caridade, 2019, 2011; Caridade et al., 2014).

Students are encouraged to share their work as a scientific communication through poster or oral presentation. The poster is a way for the student to socialize and draw attention to the work done, allowing a more personal, time-free iteration with their peers or teacher. The main challenge for the student who chooses this form of communication is to attract colleagues. In the Figure 8 you can see two examples of posters made by the students.

Oral presentations have limited time and include questions from peers or the teacher. In this type of communication, the student will have a wide audience and a favorable environment for discussion and analysis of the work presented. In any of the modalities the teacher has a guiding role.

\section{MONITORING AND EVALUATION}

The development of a new modality of formation needs to be monitored and evaluated so that the consolidation of practices takes place in a solid and consistent way (Gomes, 2009). There is already some information on higher education assessments, such as Caridade (2011), Ibrahim et al. (2012), Costicã (2014) which shows that the application of new technologies to learning mathematics has a positive effect in reducing dropout rates. In addition, Garg and Kaundal (2017) also evaluated students' interest in using LA in computer vision because they provide more truthful and close solution to the real-world problems. The references Zin et al. (2015), Ohrstrom et al. (2005) revealing that students seem to appreciate the contribution of these transforming teaching 
Table 2. Profile of CIE students who did the practical work in the 2018/2019 school year

\begin{tabular}{ll}
\hline Students profile & Description \\
\hline Students & 1 st Year of Mechanical and Electromechanical Engineering \\
\hline $\mathrm{N}^{\circ}$ of Students & $58(57$ males and 1 females $)$ \\
\hline Mean of ages & 20.55 (ages between 18 and 35 years $)$ \\
\hline Residence & $34.5 \%$ Coimbra and $83 \%$ of the districts Coimbra, Aveiro, Leiria, Viseu, Santarém. \\
\hline Work situation & $15.5 \%$ of students are student workers. \\
\hline Course & $24 \%$ Electromechanical Engineering; $76 \%$ Mechanical Engineering \\
\hline Year of admission to the course & $57 \%$ in 2018 and $43 \%$ in previous years. \\
\hline
\end{tabular}

and learning approach to their lectures. With these experiences enables the evaluation of several cross skills and competencies such as critical thinking and ethical leadership as Izquierdo says (Izquierdo et al., 2016).

This project has been monitoring and evaluated in a systematic way. The assess to teaching and learning of the students and theirs interest and satisfaction are one of the main points to the developed of the practical project proposed. In this sense, a questionnaire was made in Moodle platform to evaluate the importance in developing, projects like this one, by engineering students, in motivating and learning LA contents.

\section{DESCRIPTION AND RESULTS OF THE STUDY}

In Polytechnic of Coimbra-Institute of Engineering, since 2016, in LA-CU of Electromechanical and Mechanical Engineering, the students develop practical projects as a complement to the classes. In first semester of 2018-19, 58 students answered a questionnaire to evaluate students' motivation and interest in doing the practical project. The questionnaire was designed to identify the type of student and their opinion regarding the course, the CU and the practical project (Caridade, 2019). Data were processed using SPSS software version 21.

\section{Characteristics of the Students}

The student characterization is represented in Table 2. From the 58 students, one is female, with a mean age of 21 years, $15.5 \%$ of student are student workers, mostly residence outside Coimbra city (83\%), 44 (76\%) are in Mechanical Engineering and $14(24 \%)$ in Electromechanical Engineering and a total of $43 \%$ students who have not completed LA in previous years.

The students involved in this study are first- and second-year students, quite new, who had no contact with image processing and who had very little contact with Matlab software. Their experience with this type of project is practically none. Therefore, some students may not be motivated to do the practical project because they have little time available (for example student workers) to learn how to use Matlab and prepare the requested project (Caridade, 2019).

\section{Choice of Course}

The reasons that lead students to choose a school or course are factors that condition their commitment. The quality of education is the most frequent choice for PC-IE (46\%), followed by the recommendation of friends $(11 \%)$. That is, almost half of the students are enrolled in PC-IE for the quality of teaching. The main motivation to attend the degree was the identification with the course $(60 \%)$ and then the opportunities offered by the course $(29 \%)$. The degree of satisfaction they have in relation to the chosen course is satisfactory $(50 \%)$, very satisfactory $(38 \%)$ and only $12 \%$ indicates a regular satisfaction. That is, more than $88 \%$ of students are satisfied with the course they have chosen (Caridade, 2019).

\section{Functioning and Organization of the CU}

To evaluate the quality of the CU a Likert-type scale was used, with a degree of agreement ranging from 1 to 5 , as follows: 1- Very unsatisfactory, 2- Unsatisfactory, 3- Regular, 4- Satisfactory, 5- Very satisfactory. The students interviewed do not attend in the same classes do not all have the same teachers. Students on average are satisfied with the course (28 Satisfactory, 22 Very satisfactory and 6 Regular). Table 3 shows the mean and standard deviation of the responses obtained to the 6 questions in relation to the quality of LA-CU.

Few students identified regular or unsatisfactory aspects regarding the quality of teaching of CU (DP- 10\% regular, RTP- 10\% regular and 5\% unsatisfactory, CC- 15\% regular, TRE- $12 \%$ regular, PIU and A- 16\% regular and $2 \%$ unsatisfactory). The remaining students answered positively to the quality of CU with an average of 4 (Satisfactory) which demonstrates the relevance and interest of the activities involved in CU.

The evaluation of the teacher's role in motivation, explanation and support throughout the teaching and learning process was assessed by 4 questions with the same kind of answers as the previous questions. The answers obtained (Table 3-last 4 lines) were only regular, satisfactory and very satisfactory, and the average in the 4 answers 
Table 3. Evaluation of the functioning and organization of the CU

\begin{tabular}{lcc}
\hline Question & Median & Standard deviation \\
\hline Didactic processes (DP) & 4.07 & 0.525 \\
\hline Relationship between theory and practice (RTP) & 4.02 & 0.737 \\
\hline Curricular Contents (CC) & 3.97 & 0.529 \\
\hline Teaching, research and extension (TRE) & 4.02 & 0.513 \\
\hline Pedagogical instruments used (PIU) & 4.00 & 0.649 \\
\hline Assessment (A) & 4.03 & 0.674 \\
\hline Relationship student teacher & 4.59 & 0.622 \\
\hline Attention of the teacher to doubts & 4.60 & 0.591 \\
\hline Teacher ethics & 4.52 & 0.569 \\
\hline Attendance of the teacher & 4.59 & 0.622 \\
\hline
\end{tabular}

Table 4. Interest and motivation of practical project

\begin{tabular}{lcc}
\hline Consolidation of learning & Average & Standard deviation \\
\hline Matrices & 4,03 & 0,556 \\
\hline Types of matrices & 4,02 & 0,574 \\
\hline Dimension of matrices & 3,97 & 0,642 \\
\hline Operations with matrices & 4,03 & 0,668 \\
\hline Properties of operations with matrices & 4,59 & 0,558 \\
\hline
\end{tabular}

is very satisfactory. It was found that less than 5 students answered "regularly" in the 4 questions, so it can be concluded that students like and agree with the way the teacher is available and supports them.

\section{Interest and Motivation of Practical Project}

Some students' knowledge of Matlab software give a make difference in the calculus of the estimated time to complete the project. So, it is necessary 2 to 3 days for 17 students (29\%), 1 week for 22 students (38\%), 2 weeks for 12 students $(21 \%)$ and more than 3 weeks for 7 students $(12 \%)$.

Almost all students agree that the Matlab project is interesting $(100 \%)$, useful $(88.7 \%)$ and allows motivating learning $(90.9 \%)$ of the matrix calculation. 4 new questions were elaborated to evaluate the dedication and commitment in terms of the learning and consolidation of the contents covered in the CU. The evaluation was done according to a Likert scale by choosing one of the 5 options: 5-I totally agree, 4 - I agree, 3 - Neither agree nor disagree, 2 - Disagree and 1 - I totally disagree. In Table 4 it can be see that students agree that the development of the practical project allows the consolidation of their knowledge in matrices, types and dimensions of matrices as well as in operations and properties between matrices (Caridade, 2019).

In an open answer, the students were asked what they liked most during the execution of the developed project. The most significant responses were as follows:

- Motivation for using new tools.

- Explore content differently.

- Manipulation of Images as Matrices.

- Further clarification of content.

Regarding what the students disliked, the answers focused on the time spent and the errors that arise during the project. Words like "interesting", "motivating", "experience", "knowledge" and "consolidate" are most frequencies and indicate a positive opinion from the students about the practical project. To see the word's cloud obtained to this question see the previous paper (Caridade, 2019).

\section{CONCLUSIONS AND FUTURE WORK}

The development of the interconnection between DIP and LA arises from the interest in promoting a learning of the LA contents in a motivating way to the Coimbra Institute of Engineering students. In this way, it intends to improve the teaching and learning practices of the LA for students of Mechanical and Electromechanical Engineering of Coimbra Institute of Engineering and possibly the extension to other courses.

Although the experience has been limited to some LA contents, the importance of this type of methodology justifies its presentation. By the way, based on the student's opinion, it is evident that learning is more exciting when using a different methodology that can motivate the interest of the students. This can be seen by the feedback from students. Most of the students enjoy it and they were very active (almost all the enquiry students). This methodology proves to be a viable and effective way of teaching and learning LA. More activities are needed to learn LA concepts more consistently by applying practical results to different images. 
In this school year the project already includes other IP activities applied to LA such as simple object counting. The student will have to create an image consisting of different geometric figures of different colors and develop an application that automatically counts the total number of objects as well as the number of objects of a given color. Other activities including LA content related to eigenvalues and eigenvectors are also being considered.

It is also intended to apply the evaluation model described in Machado and Gomes (2013) using the dimensions: subject (students and teachers); pedagogical and organizational and technology (support technologies and support structures and services), to identify different factors to consider in the evaluation. It is also suggested as a future work, that a satisfaction questionnaire be made annually to students and teachers as a means of quantifying the satisfaction of all those involved in the teaching and learning process, identifying problems and making the necessary modifications for the good operation of the practical project.

\section{REFERENCES}

Berriochoa, E., Cachafeiro, A. and Illán, J. (2009). An approach for teaching the linear algebra for students of engineering. Proc. of International Conference of Education, Research and Innovation, pp. 3756-3763.

Bovik, A. (2000). Handbook of Image and Video processing. San Diego, CA: Academic Press. https:/ / doi.org/10.1016/B978-0-12-119792-6.X5062-1

Caridade, C. M. R. (2011). Applying image processing techniques to motivate students in linear algebra classes. Proc. of the 1st World Engineering Flash Week, Lisbon 2011, 114-121.

Caridade, C. M. R. (2019). Linear Algebra and Image Processing: a new teaching approach. In 2019 14th Iberian Conference on Information Systems and Technologies (CISTI), IEEE, 1-6. https://doi.org/10.23919/CISTI.2019.8760909

Caridade, C. M. R., Encinas, A. H., Martín-Vaquero, J. and Queiruga-Dios, A. (2014). CAS and real life problems to learn basic concepts in Linear Algebra courses. Computer Apllications in Engineering Education, $23(4), 567-577$. https://doi.org/10.1002/cae.21627

Costicã, L. (2014). The contribution of the new technologies to learning mathematics. Procedia - Social and Behavioral Sciences, 128, 240-245. https://doi.org/10.1016/j.sbspro.2014.03.150

Donevska-Todorova, A. (2018) Fostering Students' Competencies in Linear Algebra with Digital Resources. In: S. Stewart, C. Andrews-Larson, A. Berman and M. Zandieh (eds.) Challenges and Strategies in Teaching Linear Algebra. ICME-13 Monographs. Springer, Cham. https://doi.org/10.1007/978-3-319-66811-6_12

Garg, A. and Kaundal, K. (2017). A study of Linear Algebra for Computer Vision. International Journal of Innovative Research in Compute and Communication Engineerin, 3, 4169-4176. https://doi.org/10.15680/IJIRCCE.2017. 0503081

Garía, I. and Cano, E. (2018). A computer game for teaching and learning algebra topics at undergraduate level. Comput. Appl. Eng. Educ, 26(2), 326-340. https://doi.org/10.1002/ cae.21887

Gomes, M. J. (2009). Problemas da avaliação em educação online. Educação online: cenário, formação e questões didáticometodológicas. Rio de Janeiro: WAK, 309-336.

Gonzalez, R. C., Woods, R. E. and Eddins, S. L. (2009). Digital Image Processing Using MATLAB (2nd Ed.). Gatesmark Publishing.

Ibrahim, R., Bakri, N., Salleh, T. S. A. and Zin, Z. M. (2012). Incorporating mathematics in teaching and learning of image processing. 4th International Congress on Engineering Education. https://doi.org/10.1109/ICEED.2012.6779260

Izquierdo, J., Benítez, J., Berenguer, A. and Lago-Alonso, C. (2016). I decide, therefore I am (relevant!): A project based learning experience in linear algebra. Computer Apllications in Engineering Education, 24(3), 481-492. https://doi.org/10.1002/cae.21725

Machado, C. and Gomes, M. J. (2013). Avaliação de cursos b-learning: uma proposta. Atas da VIII Conferência Internacional de Tecnologias da Informação e Comunicação - Challenges, 1635-1642.

Mathsisfun.com (n.d.). Sam Loyd Puzzles. Available at: https://www.mathsisfun.com/puzzles/sam-loyd-puzzlesindex.html/

Notícias ao Minuto (n.d.). Palestras sobre a canção de Coimbra terminam com homenagem à guitarra. Available at: https://www.noticiasaominuto.com/amp/705258

Ohrstrom, L., Svensson, G., Larsson, S., Christie, M. and Niklasson, C. (2005). The pedagogical implications of using MATLAB in integrated chimestry and mathematics courses. International Journal of Engineering Education, 21(4), 683-691.

Pinterest (n.d.). Ballerina dancing on the beach | The best wallpapers collection ... | Dance, Ballerina dancing, Dance poses. Available at: https://www.pinterest.de/pin/247135098280420209/ 
Produto.mercadolivre.com.br (n.d.). Mercado Livre Brasil - Onde comprar e vender de Tudo. Available at: https:/ / produto.mercadolivre.com.br/MLB-740979663-azulo-treine-seu-passaro-de-maneira-profissional150-cantos-_JM?quantity=1

Silverman, J. and Rosen, G. (2010). Supporting students interest in mathematics throught applications from digital image processing. Journal of the Research Center for Education Technology, 6(2), 63-77.

Thetapestryhouse.com (n.d.). van Gogh Starry Night - French tapestry wallhanging. Available at: https://www.thetapestryhouse.com/tapestries/view/1026/van-gogh-starry-night

wikipedia.org (n.d.a). The Division Bell. Available at: https://en.wikipedia.org/wiki/The_Division_Bell

wikipedia.org (n.d.b). Animals (Pink Floyd album). Available

at: https://en.wikipedia.org/wiki/Animals_(Pink_Floyd_album)

wikipedia.org (n.d.c). Available at: https://pt.wikipedia.org/wiki/Universidade_de_Coimbra_Alta_e_Sofia\#/ media/Ficheiro:Coimbra_December_2011-19a.jpg

Zin, Z. M., Sallehb, T. S. and Bakrib, N. (2015). Transforming Teaching and Learning Approach of Mathematics and Image Processing. Journal of Science and Engineering Technology, 2(2). 